\title{
Combined EsophaCap cytology and MUC2 immunohistochemistry for screening of intestinal metaplasia, dysplasia and carcinoma
}

This article was published in the following Dove Press journal: Clinical and Experimental Gastroenterology

\author{
Zhongren Zhou' \\ Irina Kalatskaya ${ }^{2}$ \\ Donna Russell' \\ Norman Marcon ${ }^{3}$ \\ Maria Cirocco ${ }^{3}$ \\ Paul M Krzyzanowski ${ }^{2}$ \\ Cathy Streutker ${ }^{3}$ \\ Hua Liang ${ }^{4}$ \\ Virginia R Litle ${ }^{5}$ \\ Tony E Godfrey \\ Lincoln Stein ${ }^{2}$ \\ 'Department of Pathology \& \\ Immunology, Washington University, \\ Saint Louis, MO, USA; ${ }^{2}$ Department of \\ Adaptive Oncology, Ontario Institute for \\ Cancer Research, Toronto, Ontario, \\ Canada; ${ }^{3}$ Division of Gastroenterology, \\ Department of Internal Medicine, \\ St. Michael's Hospital, Toronto, Ontario, \\ Canada; ${ }^{4}$ Department of Statistics, \\ George Washington University, \\ Washington, DC, USA; ${ }^{5}$ Department of \\ Surgery, Boston University School of \\ Medicine, Boston, MA, USA
}

Purpose: The incidence of esophageal adenocarcinoma (EAC) has increased by $700 \%$ in Western countries over the last 30 years. Although clinical guidelines call for endoscopic surveillance for EAC among high-risk populations, fewer than 5\% of new EAC patients are under surveillance at the time of diagnosis. We studied the accuracy of combined cytopathology and MUC2 immunohistochemistry (IHC) for screening of Intestinal Metaplasia (IM), dysplasia and EAC, using specimens collected from the EsophaCap swallowable encapsulated cytology sponge from Canada and United States.

Patients and methods: By comparing the EsophaCap cytological diagnosis with concurrent endoscopic biopsies performed on the same patients in 28 cases, we first built up the cytology diagnostic categories and criteria. Based on these criteria, 136 cases were evaluated by both cytology and MUC2 IHC with blinded to patient biopsy diagnosis.

Results: We first set up categories and criteria for cytological diagnosis of EscophaCap samples. Based on these, we divided our evaluated cytological samples into two groups: nonIM group and IM or dysplasia or adenocarcinoma group. Using the biopsy as our gold standard to screen IM, dysplasia and EAC by combined cytology and MUC2 IHC, the sensitivity and specificity were $68 \%$ and $91 \%$, respectively, which is in the range of clinically useful cytological screening tests such as the cervical Pap smear.

Conclusions: Combined EsophaCap cytology and MUC2 IHC could be a good screening test for IM and Beyond.

Keywords: Barrett's esophagus, esophageal adenocarcinoma, cytology screening, MUC2 IHC, EsophaCap, intestinal metaplasia

\section{Introduction}

The incidence of esophageal adenocarcinoma (EAC) is rising rapidly in Western countries, having increased 6-7 folds in North America since the 1980s. ${ }^{1}$ EAC is a devastating disease that carries an overall 5-year survival of only $18-22 \%{ }^{2}$ Part of the reason for EAC's poor prognosis is that most patients present at an advanced stage when they experience obstructive symptoms such as discomfort on swallowing. The single major risk factor for the development of EAC is Barrett's esophagus (BE), a metaplastic condition in which intestinal-like glandular epithelium replaces the normal squamous mucosa of the esophagus. $\mathrm{BE}$ is a consequence of chronic gastroesophageal reflux disease (GERD). ${ }^{3,4}$ Roughly $15-40 \%$ of the adults in western countries have GERD, while $8-20 \%$ of the GERD adults develop BE.,6 Patients with BE have between a $0.12 \%$ and $0.5 \%$ annual rate of progression to
Correspondence: Zhongren Zhou Department of Pathology and Immunology, Washington University, 660

South Euclid Campus Box 8118, Saint

Louis, MO 63110-1093, USA

$\mathrm{Tel}+|3| 4747$ |397

Fax +I 3143624096

Email zhongrenzhou@wustl.edu 
EAC, and an 11.3-40-fold increase in their lifetime risk of developing $\mathrm{EAC}$ in comparison to the non-BE population. ${ }^{7-10}$

In most western countries, clinical guidelines recommend that patients with chronic GERD obtain a baseline endoscopy to diagnose BE. ${ }^{11,12}$ Patients with $\mathrm{BE}$ are then recommended to undergo periodic endoscopic surveillance with biopsy to detect progression to dysplasia and EAC. ${ }^{11,12}$ However, in practice endoscopic surveillance of patients with $\mathrm{BE}$ requires loss of a partial work day for the patient, involves sedation and has a low but real complication rate. ${ }^{13-15}$ For these reasons, many patients and their providers are reluctant to commit to endoscopy. Furthermore, endoscopy is expensive in comparison to other screening technologies such as mammography, and its cost-effectiveness is in doubt. ${ }^{14}$ Consequently, just 5\% population that is thought to have $\mathrm{BE}$ is under surveillance. ${ }^{7,16-19}$ Therefore, there is an urgent need to develop new methods to screen patients with GERD for $\mathrm{BE}$ and to surveil $\mathrm{BE}$ patients for progression.

Esophageal balloon cytology has been used in China to screen for esophageal squamous cell carcinoma ${ }^{19-22}$ and in the USA to detect esophageal carcinoma. ${ }^{23,24}$ Nonendoscopic screening methods based on swallowable encapsulated sponges have been developed in the United Kingdom, ${ }^{25-27}$ Switzerland ${ }^{28}$ and in the USA. These tests are administered in the form of a sponge-containing gelatin capsule attached to a string or tether that the patient swallows like a pill. The sponge expands after swallowing and is then retrieved with the tether. During retrieval, the sponge scrapes the esophageal mucosa, collecting epithelial cells for further cytological, immunohistochemical or genetic analysis. In several large studies, swallowable encapsulated sponges were well accepted by patients enrolled in BE surveillance programs. ${ }^{27,29,30}$ Fitzgerald's group in the UK has reported IM detection using trefoil factor 3 (TFF3) immunohistochemistry on cell blocks obtained via the Cytosponge ${ }^{\mathrm{TM}}$ sampling. The overall sensitivity of the test was $79.9 \%$, increasing to $87.2 \%$ for patients with $\geq 3 \mathrm{~cm}$ of circumferential intestinal metaplasia (IM) ${ }^{25}$ However, the accuracy of swallowable encapsulated sponges for the detection of dysplasia and/or cancer by combined cytopathology and immunohistochemistry has not been reported.

In the current study, we used EsophaCap ${ }^{\mathrm{TM}}$ sampling to obtain esophageal cytology specimens at two North American sites (Canada and the USA) from 169 patients with known GERD, BE or dysplasia undergoing routine endoscopic examination. The sponge cytology specimens were examined cytologically alone and in combination with MUC2 immunohistochemistry (IHC). The sensitivity, specificity and accuracy of these methods for detecting intestinal metaplasia, dysplasia and EAC were analyzed.

\section{Materials and methods}

\section{Patient recruitment and demographics}

We recruited adult $\left(18^{+}\right)$patients with previously documented gastroesophageal reflux disease, BE, or low- or high-grade dysplasia undergoing routine surveillance, diagnostic and/or therapeutic endoscopy at either the St. Michael's Hospital Endoscopy Unit in Toronto, Canada (159 patients), or the Boston University in Boston, MA, USA (10 patients). We excluded subjects for whom esophageal biopsy or sponge sampling would be contraindicated, such as those with known esophageal strictures. Patients gave written informed consent to participate in the study, and this study was conducted in accordance with the Declaration of Helsinki. The research ethics committees approved the study at all clinical and research sites.

As of September 2016, 250 patients were recruited at St. Michael's hospital and Boston University Medical Centre. Six patients elected not to attempt to swallow (2.4\%). Seventy-five patients tried but were not able to swallow (30\%). One hundred and sixty-nine esophageal cytology specimens were collected. The major complaint was gagging, reported by $65 \%$ of the patients able to swallow.

The patient cohort included $80 \%$ males and $20 \%$ females with a mean age of 65.8 years. The vast majority of the studied patients were white $(96 \%)$ and had a history of current or past cigarette smoking (72\%).

\section{Esophageal cytology collection}

The EsophaCap $\left({ }^{\mathrm{TM}}\right)$ is a gelatin capsule containing a compressed sponge attached to a tether (Figure 1). We purchased EsophaCaps $\left({ }^{\mathrm{TM}}\right)$ from Capnostics LLC (Doylestown PA). Esophageal cytology samples were collected by a registered nurse prior to sedation for endoscopy. The patient swallowed the capsule with a drink of water while holding the tether loosely. In 5 mins after allowing the capsule to dissolve in the proximal stomach, it released a spherical polyurethane sponge in two sizes, $2.5 \mathrm{~cm}$ and $3.0 \mathrm{~cm}$ in diameter. The back of the throat was then sprayed with $1 \%$ lidocaine (lignocaine) and the expanded sponge was then 

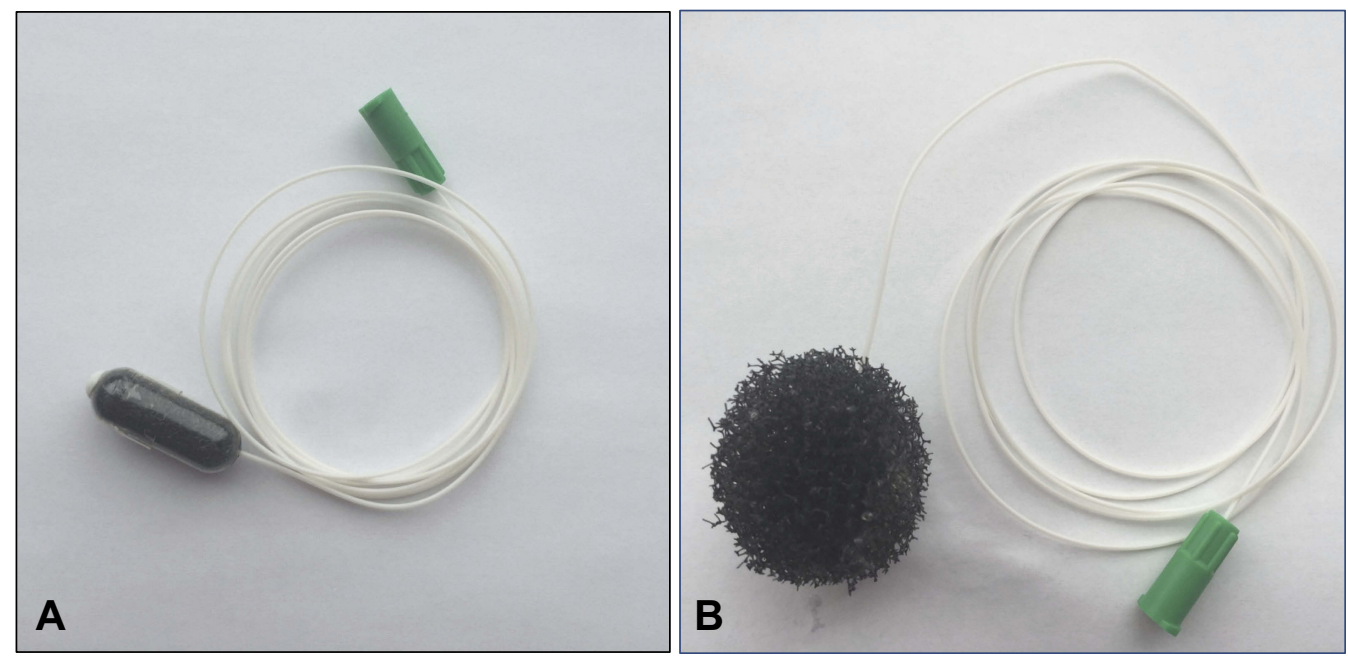

Figure I EsophaCap is an encapsulated sponge (A) attached to a tether (B).

withdrawn by pulling on the tether. After sponge retrieval, the tether was cut and the sponge containing the cytological specimen was placed in preservative fluid (CytoLyt) and kept refrigerated prior to transport to the University of Rochester Pathology department for cytology processing.

\section{Endoscopy and biopsy}

Subsequent to sponge cytology collection, typically within $1 \mathrm{hr}$, patients underwent routine endoscopic examination with biopsy sampling. The biopsies were processed and examined at the Surgical Pathology units at St. Michael's Hospital and Boston University for routine diagnosis. The first 28 biopsy slides were then transmitted to the University of Rochester for review by the study GI pathologist (ZZ). The rest of the biopsy cases were diagnosed by local GI pathologists.

\section{Cytopathology sample preparation}

All specimens were preserved in CytoLyt solution and processed on the Thin Prep Processor (ThinPrep 2000, HOLOGIC, MA) using the standard Non-Gyn protocol. Cell blocks were prepared as follows: the specimen was centrifuged to produce a concentrated cell button $(5 \mathrm{~min} /$ $349 \mathrm{~g}$ ) that was resuspended in $5 \mathrm{ml}$ buffered formalin and centrifuged again $(5 \mathrm{~min} / 349 \mathrm{~g}$ ) to produce a fixed cell button. The cell button was then paraffin embedded and sectioned. Two unstained slides were cut for each sample. One slide was stained with hematoxylin and eosin, and the other was sent for MUC2 IHC. All ThinPrep slides and cell blocks were submitted for cytopathology (ZZ) and senior cytotechnologist (D. Russell) review.

\section{Cytopathology diagnostic criteria and categories}

Based on our review of the first 28 paired cases and previous cytological classification systems for the esophagus, ${ }^{31,32}$ we developed criteria and categories to classify the glandular cells observed in the ThinPrep and cell block samples (Table 1). Based on the morphological criteria, 136 cases were evaluated by one cytopathologist and one senior cytotechnologist, both blinded to patient information and the paired biopsy diagnosis. The number of all glandular cells and squamous cells were counted.

\section{Histologic study of FFPE biopsy specimens}

All biopsies were reviewed by gastrointestinal pathologists in St. Michael hospital and Boston Medical Center. The new definition for $\mathrm{BE}$ by American College of Gastroenterology is "BE should be diagnosed when there is an extension of salmon-colored mucosa into the tubular esophagus extending $\geq 1 \mathrm{~cm}$ proximal to the gastroesophageal junction (GEJ) with biopsy confirmation of intestinal metaplasia. (IM)" ${ }^{, 11}$ Since the length of mucosa is required for the diagnosis of BE. The pathology cannot directly diagnose the $\mathrm{BE}$ instead of intestinal metaplasia (IM). The histologic diagnoses were categorized into six categories (see Table 1) including normal squamous epithelium (SE), columnar cell metaplasia (CM), intestinal metaplasia (IM), indefinite dysplasia (ID), low-grade dysplasia (LGD), high-grade dysplasia (HGD) and EAC. Based on ACG guideline for BE, BE should be diagnosed when there is extension of salmon-colored mucosa into the tubular esophagus extending $\geq 1 \mathrm{~cm}$ proximal to the gastroesophageal junction with biopsy confirmation of IM. ${ }^{11}$ Therefore, our diagnosis from pathology biopsy has to be 
Table I Diagnostic categories of esophageal glandular cells in EsophaCap cytology sample

\begin{tabular}{|l|l|l|}
\hline Cytology categories & Criteria for cytological diagnosis & $\begin{array}{l}\text { Matched } \\
\text { biopsy }\end{array}$ \\
\hline $\begin{array}{l}\text { Non-diagnostic (ND) } \\
\text { No or rare columnar cell (NCC) }\end{array}$ & $\begin{array}{l}\text { Scant squamous cellularity, extensive bacteria or blood and poor preservation } \\
\text { Normal squamous cells with less than } 4 \text { groups glandular cells in cell block }\end{array}$ \\
$\begin{array}{l}\text { Columnar cell with no goblet cell } \\
\text { (CCNGC) }\end{array}$ & $\begin{array}{l}\text { Large flat, cohesive sheets of glandular cells with distinctly outlined, smooth, sharply } \\
\text { defined edges; uniform round or oval nuclei in the basal layer; MUC2 IHC negative } \\
\text { grade dysplasia (IMNHGD) } \\
\text { Atypical glandular cells (AGC) } \\
\text { round or oval nuclei in the basal layer or focal nuclear stratification and hyperchromasia; } \\
\text { goblet cells more ready present in cell block, positive for MUC2 IHC } \\
\text { Small or large flat sheets of atypical gland cells with nuclear enlargement, uniform, promi- } \\
\text { nent nucleoli, increased N/C ratios, smooth nuclear membranes; fine chromatin, positive } \\
\text { MUC2 IHC } \\
\text { Rare atypical cells with hyperchromasia, pleomorphism, prominent nucleoli, irregular } \\
\text { nuclear contour and thickened membrane, overlapping, loss of polarity, and rare atypical } \\
\text { Cuspicious for EAC (SFEAC) }\end{array}$ & $\begin{array}{l}\text { ID } \\
\text { mitoses } \\
\text { Small 3-dimensional clusters of atypical glandular cells with prominent nucleoli, irregular } \\
\text { nuclear contours, high N/C ratio, loss of polarity, hyperchromasia, pleomorphism, frequent } \\
\text { mitosis and focal necrosis (tumor diathesis), some atypical single cells }\end{array}$ \\
Esophageal adenocarcinoma (EAC)
\end{tabular}

Abbreviations: IM, intestinal metaplasia; CM, columnar cell metaplasia; EAC, esophageal adenocarcinoma; HGD, high-grade dysplasia; ID, indefinite dysplasia; LGD, lowgrade dysplasia; SE, squamous epithelium.

changed to IM instead of BE. The histological diagnosis was executed independently from the cytological diagnosis. Five cytology cases did not have matched biopsy diagnosis, which were excluded from the statistics.

Construction of tissue microarray. MUC2 immunostain was evaluated by tissue microarrays (TMA) that included 33 cases of BE, 64 cases of CM, 95 cases of SE, 31 cases of LGD, 8 cases of HGD and 109 cases of EAC were constructed from the representative areas of FFPE specimens collected between 1997 and 2005 at the Department of Pathology and Laboratory Medicine, University of Rochester Medical Center, New York. Five-micron sections were cut from the tissue microarrays and were stained with H\&E to confirm the presence of the expected tissue histology within each tissue core. Additional sections were cut for MUC2 IHC.

\section{MUC2 IHC on cell blocks and TMA}

Tissue sections from the cell block and esophageal TMA were deparaffinized, rehydrated through graded alcohols, and washed with phosphate buffered saline. Antigen retrieval was performed by heating sections in $99^{\circ} \mathrm{C}$ water bath for 30-40 mins. After endogenous peroxidase activity was quenched and nonspecific binding was blocked, antibody for MUC2 (DAKO, CA) was incubated at room temperature for 30 mins. The secondary antibody (Flex HRP, DAKO, CA) was allowed to incubate for 30 mins. After washing, sections were incubated with Flex DAB
Chromogen for 10 mins and counterstained with Flex Hematoxylin for 5 mins. A previously diagnosed BE case served as a positive control. Negative control was performed by replacing antibodies with normal serum.

Data analysis. Summary data are expressed as the means (SDs). All statistical tests are two-sided unless otherwise noted. $P$-values of less than 0.05 are considered statistically significant.

\section{Results}

\section{Criteria and categories for cytological diagnosis}

All 169 cytology specimens had adequate numbers of epithelial cells to render a diagnosis. The first 28 cases with matched surgical biopsy were used to set up the diagnostic criteria; the remaining 141 cases were diagnosed blinded to patient information and surgical biopsy diagnosis. Based on the morphology from our 28 cases with matched cytology and biopsy, and previous esophageal cytology classification systems, ${ }^{31,32}$ we developed a set of diagnostic categories for glandular cells obtained by cytology (Table 1).

\section{Analysis of cytological diagnosis}

Table 2 compares the histopathological biopsy diagnosis to the cytological diagnosis for the 141 cases that were diagnosed blindly. Five of 141 cases without matched surgical 
Table 2 Number of surgical biopsy and cytology cases with each category

\begin{tabular}{|l|l|l|l|}
\hline Biopsy Dx & \# Cases & Cytology Dx & \# Cases \\
\hline Esophageal adenocarcinoma & 29 & Esophageal adenocarcinoma & 5 \\
High grade dysplasia & 20 & Suspicious for EAC & 7 \\
Low grade dysplasia/indefinite dysplasia & $18 / I$ & Atypical glandular cells & 34 \\
Intestinal metaplasia & 55 & Intestinal metaplasia with no high grade dysplasia (IMNHGD) & 39 \\
Columnar cell metaplasia & 7 & Columnar cell with no goblet cell (CCNGC) & 16 \\
Squamous cell carcinoma & $\mathrm{I}$ & Squamous cell carcinoma & 1 \\
Squamous dysplasia & $\mathrm{I}$ & Atypical squamous cells & 1 \\
Squamous epithelium & 4 & Non-columnar cell metaplasia & 34 \\
Total & 136 & & 136 \\
\hline
\end{tabular}

Abbreviation: EAC, esophageal adenocarcinoma.

biopsy diagnosis were excluded from the analysis. Of 136 cases, 34 cases were diagnosed as no columnar cell (NCC). These Thin-Pap smears contained normal squamous cells and no or rare glandular clusters ( $\leq 3$ clusters) (Figure 2A). Fifteen columnar cell with no-goblet cell (CCNGC) cases contained predominant squamous cells and some large, flat cohesive sheets of glands with honeycomb pattern, smooth, sharp edge and small round or oval nuclei (Figure 2A) and columnar cell glands without goblet cells in cell block (Figure 2C) as well as negative MUC2 IHC (Figure 2E).

Thirty-nine intestinal metaplasia with no high-grade dysplasia (IMNHGD) cases consisted of large flat sheets of cells with focal goblet cells and smooth, sharply defined edges. The cytoplasm of goblet cells showed slightly basophilic mucin. The nuclei were small, and linearly arranged in the basal layer (Figure 2B), which could be compatible with surgical biopsy IM cases. Some nuclei showed focal nuclear stratification and hyperchromasia in a honeycomb pattern, which could be compatible with low-grade dysplasia (LGD) cases. However, the differentiation of IM and LGD is thought not to be reliable in esophageal cytology. ${ }^{31}$ Therefore, we combined these into a single IMNHGD category. Goblet cells were not easily identified in the smears but were readily identified in corresponding cell blocks (Figure 2D) and by MUC2 IHC (Figure 2F).

Atypical glandular cells (AGC) consisted of small threedimensional clusters of atypical glandular cells with nuclear enlargement, overlapping and hyperchromasia, prominent nucleoli and smooth nuclear membrane (Figure 3A and B). Cytoplasm showed decreased cytoplasmic mucin.

Suspicious for EAC (SFEAC) consisted of rare atypical cells with hyperchromasia, pleomorphism, prominent nucleoli, irregular nuclear contour and thickened membrane, overlapping, loss of polarity and rare mitosis (Figure 3C and D). EAC had similar morphologic changes, but abundant cells or clusters (Figure $3 \mathrm{E}$ and F). In addition, EAC consisted of frequent mitosis and focal necrosis (tumor diathesis). Some single, loose tumor cells were identified in EAC, but not in benign glands. One atypical squamous cell (ASC) and one squamous cell carcinoma (SCC) were diagnosed. The cytology showed high nuclear/ cytoplasm ratio, hyperchromatin, pleomorphic. However, focal goblet cells were also identified in its cell block.

\section{Estimation of glandular cell abundance}

The number and percentage of glandular cell groups in cell blocks were counted manually (Table 3). Thirty cases (22\%) had more than 30 glandular clusters. Almost half of 136 cases $(50 \%)$ had between 4 and 29 groups of glandular cells. Fifty-one cases $(37 \%)$ had $\leq 3$ glandular groups in cell blocks: 34 of 51 cases were diagnosed as NCC; 17 had more glandular cells in cytology smear or positive MUC2 immunostain in cell block to make diagnosis in glandular categories. The percentages of glandular cells in cell blocks were also counted, and the range was from $0.1 \%$ to $80 \%$. The average of glandular cells was $7.1 \%$.

\section{Evaluation of MUC2 IHC on TMA}

MUC2 was reported as highly specific markers for goblet cells metaplasia in distal esophagus and gastroesophageal junction (GEJ). ${ }^{33}$ We further performed MUC2 $\mathrm{IHC}$ in multiple cases of IM, CM, SE, LGD, HGD, and EAC on TMA and evaluated its sensitivity and specificity for detection of IM and beyond in surgical specimens (Table 4 and Figure 4). IM cases were $100 \%$ positive for MUC2 IHC but 

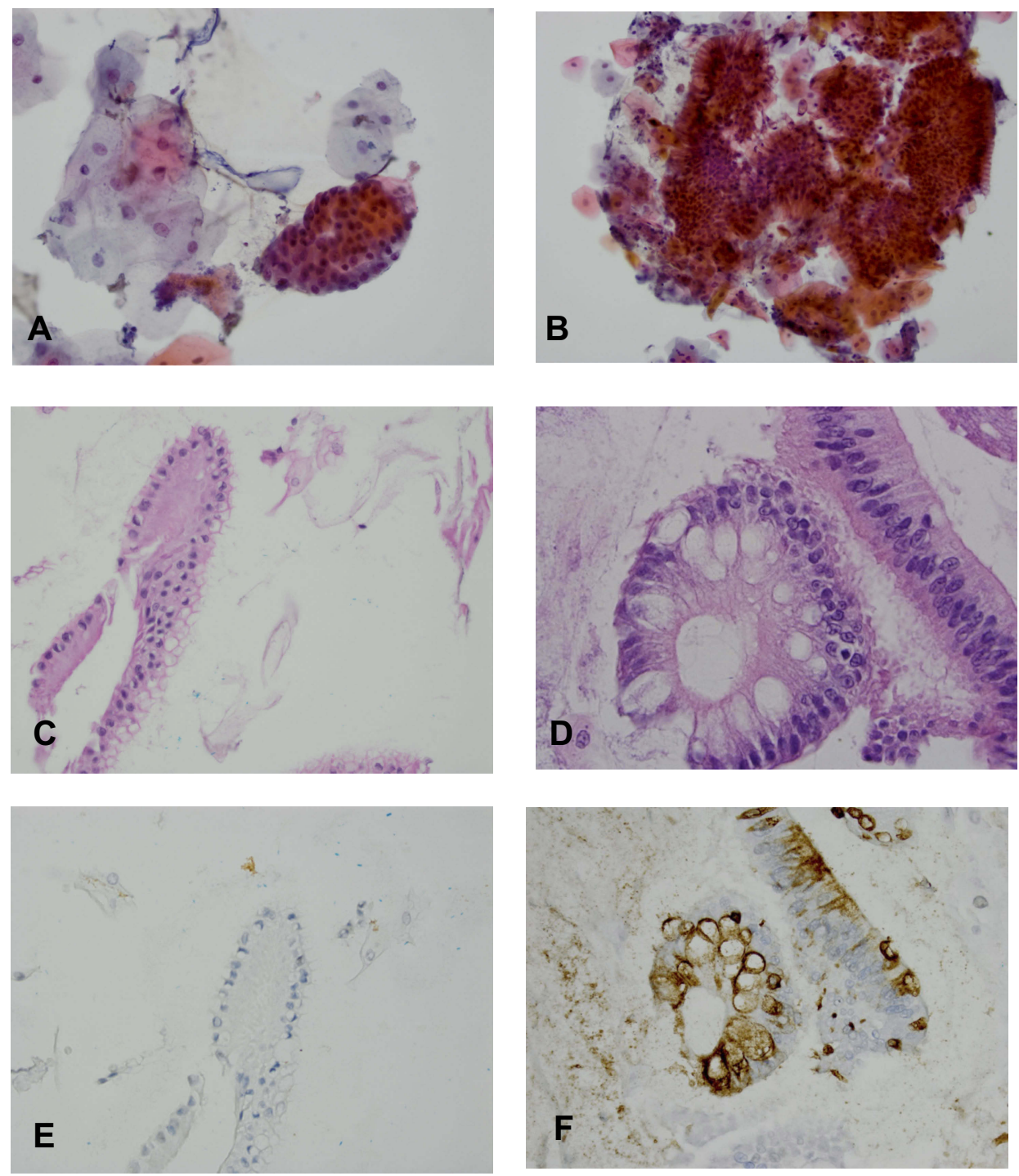

Figure 2 Intestinal metaplasia with no high-grade dysplasia (IMNHGD) and columnar cell with no goblet cells (CCNGC) of EsophaCap samples. (A) CCNGC: The specimen consists of multiple squamous cells and one sheet of glandular cells. The glandular cells are well organized. No goblet cells are identified. (B) IMNHGD: The specimen consists of multiple sheets of glandular cells. The glandular cells are well organized. Focal goblet cells are present (arrowhead). (C and E) CCNGC: One columnar cell gland is present in cell block. The columnar cells are negative for MUC2 immunostain; (D and F) IMNHGD: Goblet cells are present in cell block. The goblet cells and adjacent columnar cells are positive for MUC2 immunostain.

only positive in $50.5 \%$ of the cases of EAC. We calculated sensitivity, specificity and accuracy in two ways. First, we set $\mathrm{BE}$ as positive and $\mathrm{CM}, \mathrm{SE}$ and $\mathrm{SCC}$ as negative. The sensitivity and specificity and accuracy were $100 \%, 99.5 \%$ and $99.5 \%$. Second, we set IM, LGD, HGD and EAC as positive and CM, SE and SCC as negative. The sensitivity and specificity and accuracy were $66.9 \%, 99.5 \%$ and $83.4 \%$ due to lower positive rate of EAC cases.

\section{Combined EsophaCap cytology and MUC2 IHC for screening for $\mathrm{BE}$ and beyond}

For this phase of analysis, we asked how accurate combined cytology and MUC2 IHC would be for screening IM and beyond, in which the goal is to detect IM and more advanced disease in a patient population. We defined a "negative" biopsy as patients with surgical pathology diagnoses of $\mathrm{CM}, \mathrm{SE}$, and a negative cytology diagnosis as NCC, CCNGC in combination with a negative MUC2 IHC result. We defined a "positive" biopsy as IM, LGD, HGD and EAC, and a positive cytology as IMNHGD, AGC, SFEAC, EAC or any positive MUC2 IHC result.

By comparing the biopsy result to the cytological/IHC diagnosis, we determined that the sensitivity, specificity and accuracy for detecting IM and beyond were $67.77 \%$ (95\% CI: $58.67-75.98 \%), 90.91 \%$ (95\% CI: $58.72-99.77 \%)$ and 69.70 (95\% CI: $61.10-77.4 \%$ ), respectively. The positive 

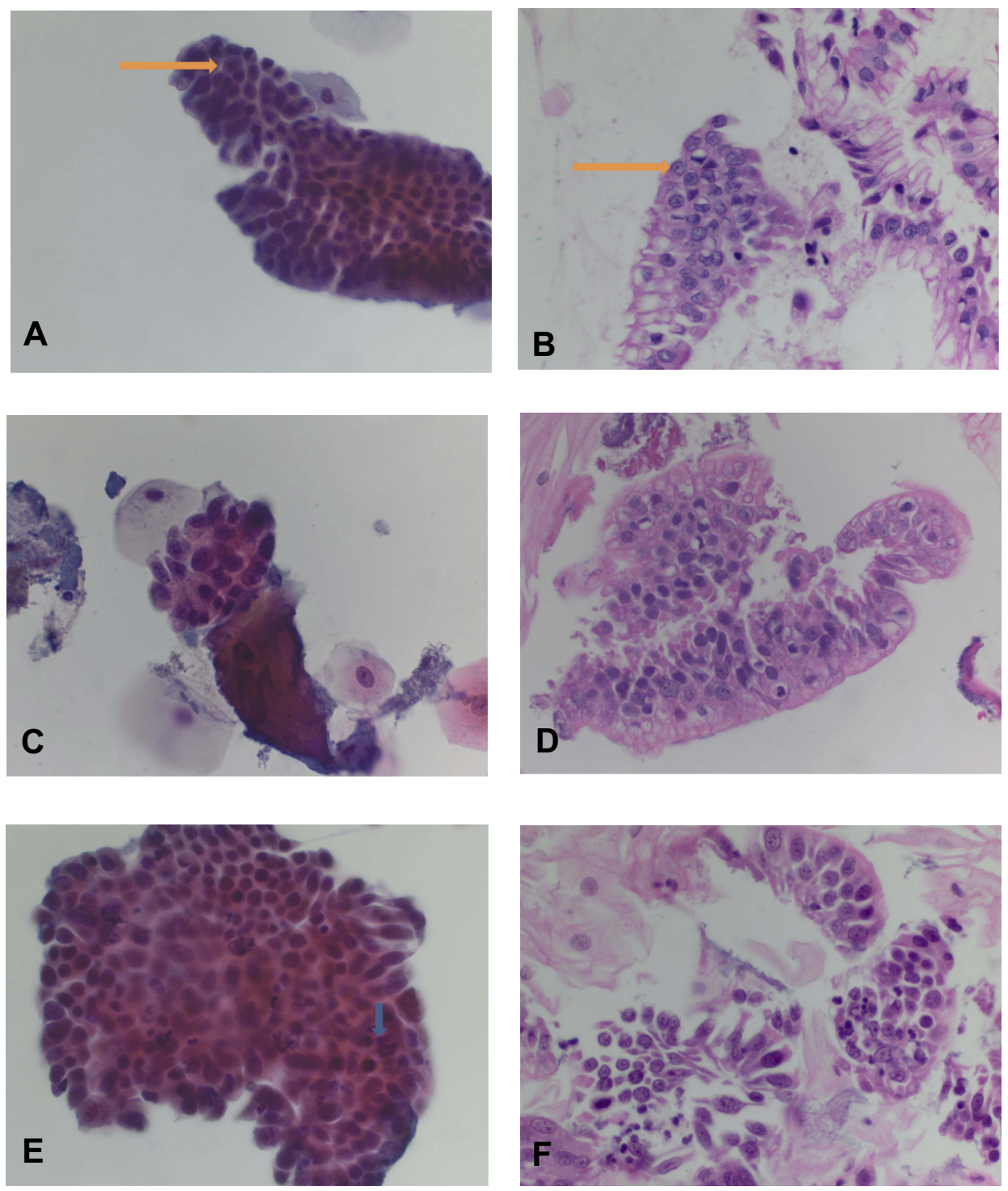

Figure 3 Atypical glandular cells (AGC), suspicious for esophageal adenocarcinoma (SFEAC) and esophageal adenocarcinoma (EAC). (A and B) AGC: The specimen consists of a sheet of glandular cells with increased nuclear size and prominent nucleoli (see arrow). (C and D) SFEAC: The specimen consists of rare cluster of glandular cells with high nuclei/cytoplasm ration, irregular nuclear contour, prominent nucleoli, hyperchromasia and overlapping. (E and $\mathbf{F}$ ) EAC: The specimen consists of multiple clusters of glandular cells with high nuclei/cytoplasm ration, prominent nucleoli, irregular nuclear contour, hyperchromasia, mitosis (see arrowhead), overlapping and the single cells.

Table 3 Number of glandular cell (GC) clusters in cell block

\begin{tabular}{|l|l|l|}
\hline GC clusters & \# Cases & Percentage (\%) \\
\hline$>30$ & 30 & 22.06 \\
$20-29$ & 7 & 5.15 \\
$10-19$ & 16 & 11.76 \\
$4-9$ & 32 & 23.53 \\
$0-3$ & 51 & 37.50 \\
Total & 136 & 100.00 \\
\hline
\end{tabular}

predictive value (PPV) and negative predictive value (NPV) were $98.80 \%$ (95\% CI: $92.65-99.81 \%)$ and $20.41 \%(95 \%$ CI: $10.71-34.00 \%)$. MUC2 IHC alone had very high specificity to identify IM and beyond (100\%), but reasonable sensitivity (79.27\%; 95\% CI: $68.89-87.43 \%)$ if we only calculate the cases with $>4$ groups of glandular cells in cell blocks. If we count all cases regardless of cellularity, the specificity to identify IM and beyond is $100 \%$, but sensitivity is $54.17 \%$ since glandular cells may or may not present in cell blocks (sample error), combined with the observation that dysplasia and $\mathrm{EAC}$ are often negative for MUC2 IHC.

\section{EsophaCap cytology for surveilling BE patients for HGD and EAC}

In the second phase of analysis, we divided the diagnostic categories in a manner compatible with a hypothetical 
Table 4 MUC2 immunohistochemistry in esophageal tissue microarray

\begin{tabular}{|c|c|c|c|}
\hline $\begin{array}{l}\text { Histological } \\
\text { Type }\end{array}$ & $\begin{array}{l}\text { Total } \\
\text { Cases \# }\end{array}$ & $\begin{array}{l}\text { MUC2 } \\
\text { positive } \\
(\%)\end{array}$ & $\begin{array}{l}\text { MUC2 } \\
\text { negative } \\
(\%)\end{array}$ \\
\hline Adenocarcinoma & 109 & $55(50.5 \%)$ & 54 (49.5\%) \\
\hline $\begin{array}{l}\text { High-grade } \\
\text { dysplasia }\end{array}$ & 8 & $8(100 \%)$ & $0(0 \%)$ \\
\hline $\begin{array}{l}\text { Low-grade } \\
\text { dysplasia }\end{array}$ & 31 & $25(80.7 \%)$ & $6(19.3 \%)$ \\
\hline $\begin{array}{l}\text { Intestinal } \\
\text { metaplasia }\end{array}$ & 33 & $33(100 \%)$ & $0(0 \%)$ \\
\hline $\begin{array}{l}\text { Columnar cell } \\
\text { metaplasia }\end{array}$ & 64 & I (I.6\%) & 185 (98.4\%) \\
\hline $\begin{array}{l}\text { Squamous } \\
\text { epithelium }\end{array}$ & 95 & $0(0 \%)$ & $95(100 \%)$ \\
\hline $\begin{array}{l}\text { Squamous cell } \\
\text { carcinoma }\end{array}$ & 27 & $0(0 \%)$ & $27(100 \%)$ \\
\hline
\end{tabular}

surveillance test designed to identify the presence of HGD or EAC in a population of patients with known IM. We defined a "negative" biopsy as one of CM, SE, IM and LGD, and a "positive" biopsy as HGD or EAC. We defined a negative cytology as one showing NCC, CCNGC and IMNHGD, and a positive cytology as AGC, SFEAC or EAC. The sensitivity, specificity and accuracy of the cytological diagnosis for distinguishing negative from positive biopsies were $40.43 \%$ (95\% CI: 26.37-55.73\%), 71.76\% (95\% CI: 60.96-81.00\%) and $60.60 \%$ (95\% CI: $51.70-69.00 \%)$, respectively. The PPV and NPV were $44.19 \%$ (95\% CI: $32.77-56.25 \%)$ and 68.54\% (95\% CI: 62.43-74.06\%).

\section{Discussion}

In the present study, we used paired biopsy and cytology specimens gathered from a cohort of 169 patients to investigate the potential utility of the EsophaCap swallowable encapsulated cytology sponge for IM screening, as well as for the surveillance of IM patients for progression to HGD and EAC. In the IM screening context, we found that with the combined cytology and MUC2 IHC, the sensitivity, specificity and accuracy for detecting IM and beyond were $67.77 \%, 90.91 \%$ and 69.70 , respectively. In the IM progression surveillance context, we were able to identify HGD/EAC with a sensitivity of $40 \%$ and a specificity of $71 \%$.

Cytological examination of esophageal cells has been used for screening and early detection of esophageal carcinoma in many countries including China, ${ }^{19-22}$ South
Africa, ${ }^{34}$ United States, ${ }^{22-24}$ Britain, ${ }^{34} \operatorname{Iran}^{35}$ and Switzerland. ${ }^{28}$ Application of a sponge-on-a-string for cytology sample collection from esophagus was reported in several studies. ${ }^{25,26,29,34}$ The Cytosponge( ${ }^{\mathrm{TM}}$ ) has been heavily studied as a tool for non-endoscopic diagnosis of BE. ${ }^{25-27}$ Using TFF3 immunostain in cell blocks, the overall sensitivity of the test for BE was $79.9 \%$, increasing to $87.2 \%$ for patients with $\geq 3 \mathrm{~cm}$ of circumferential BE. ${ }^{25,26}$ In our study, we used EsophaCap to collect esophageal samples. We focused on screening IM and beyond instead of IM only. The sensitivity is $68 \%$ relatively low for diagnosing IM and beyond, but the specificity is $91 \%$, relatively high. A lower level of sensitivity is probably due to the scant cellularity from some EsophaCap samples. Fifty-one cases (37\%) had $\leq 3$ glandular groups in cell blocks. Further improvement of the EsophaCap sampling could increase the sensitivity of this test. The Pap smear as a cervical cancer screening test is one of the most successful cancer screening tests with pooled sensitivity and specificity as $43-84 \%$ and $88-95 \%$ and HPV test has $58-94 \%$ sensitivity and $88-90 \%$ specificity. ${ }^{36-38}$ Our result has similar range of the sensitivity and specificity to screen IM and beyond compared to Pap smear and HPV tests for cervical cancer, ${ }^{37}$ which indicate that the EsophaCap combined with MUC2 IHC is a potentially good screening approach for IM and beyond.

A central aim of the current study was to establish morphological criteria for evaluating cytology obtained using the EsophaCap (TM) swallowable encapsulated sponge. A challenge in interpreting the cytology is that the sponge almost certainly samples some gastric epithelium from the GE junction before its passage through the esophagus. However, neither cytology nor histology can differentiate columnar cells originating in the stomach from columnar cell metaplasia in the esophagus. Therefore, we require the presence of goblet cells to diagnose IM and prefer to use terms such as columnar cells with no goblet cell metaplasia (CCNGC) to describe MUC2 negative glandular cells. Another challenge is the differentiation of inflammationrelated reactive atypia in columnar cell metaplasia and IM from HGD and EAC. We created a category of "atypical glandular cells" (AGC) to fit these cases (Table 1). However, 11 of 36 cytological cases called AGC had corresponding biopsies diagnosed as HGD or EAC. Therefore, we included AGC among the classes of "positives".

The diagnosis of LGD in biopsy tissues has high interobserver variability, ${ }^{38,39}$ and the diagnosis of LGD in esophageal cytology from brushing and ballooning is 

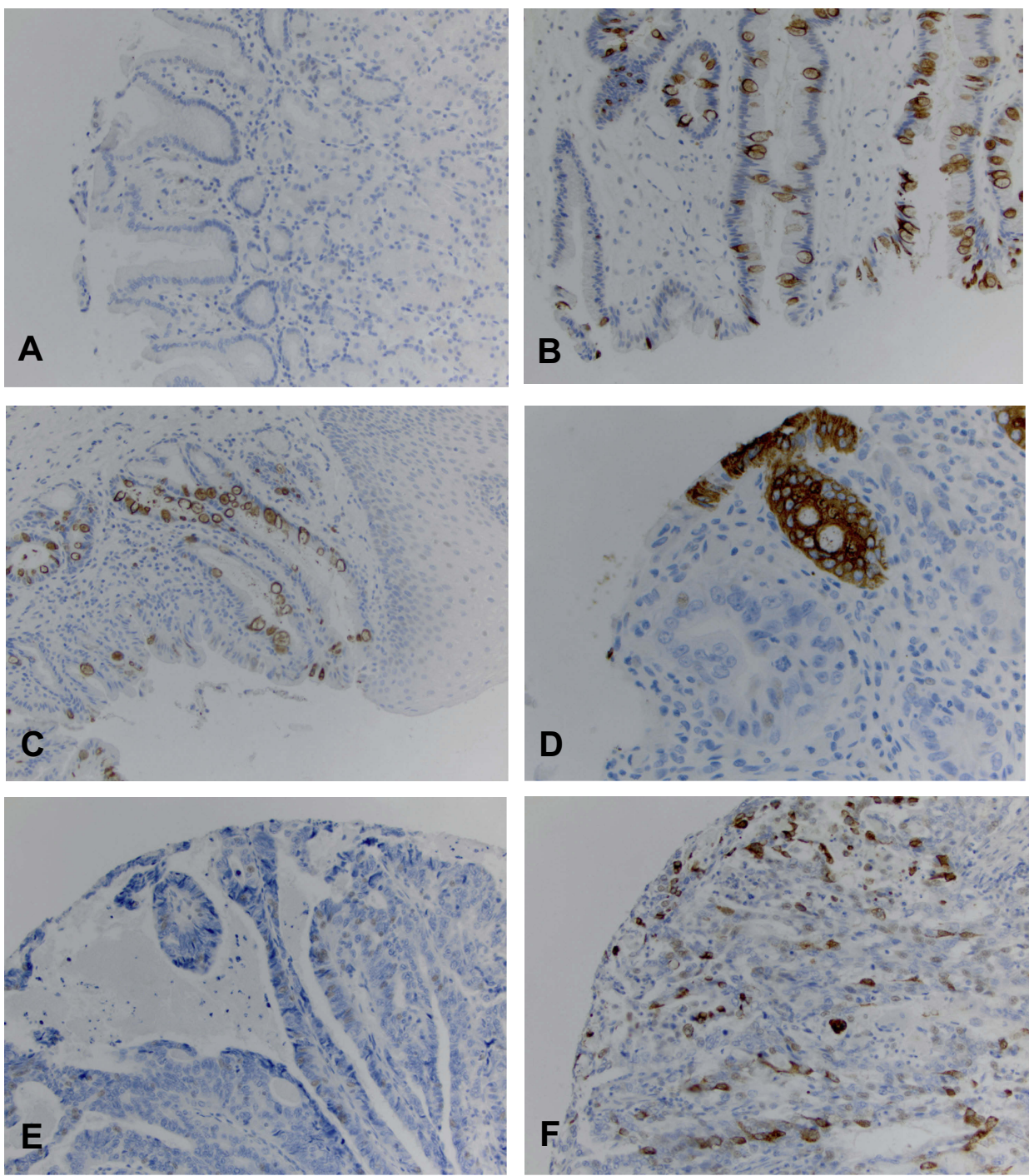

Figure 4 MUC2 immunohistochemical study (IHC) in esophageal tissue microarray (TMA). (A) Columnar cell metaplasia with negative MUC2 immunostain; (B) Barrett's esophagus with positive MUC2 immunostain; (C) Low-grade dysplasia with positive MUC2 immunostain; (D) High-grade dysplasia with positive MUC2 immunostain; (E) Esophageal adenocarcinoma with negative MUC2 immunostain; (F) Esophageal adenocarcinoma with positive MUC2 immunostain.

even more of a challenge. ${ }^{31,32,40}$ Three studies have reported that the sensitivities for detection of LGD in esophageal cytology range from $20 \%$ to $31 \%{ }^{31,32,40}$ In our study, we confirmed that it was difficult to identify LGD in Thin Pap smear and cell blocks. Therefore, we created the cytological category "intestinal metaplasia with no high-grade dysplasia" (IMNHGD) which includes specimens suspicious for low-grade dysplasia as well as IM. Cytology diagnosed as IMNHGD were concordant with a histological diagnosis of IM and LGD in 27(69.23\%) of 39 cases; nevertheless the matched biopsy of these cases showed HGD in 6/39 (15.38\%) cases and EAC in 6/39 $(15.38 \%)$ of cases. The morphology criteria for IMNHGD may need to be made more stringent in order to further reduce miscalling of HGD and EAC.
The cytological criteria for "EAC" are abundant obvious malignant cells with focal necrosis (tumor diathesis) and atypical single cells. The criteria of "suspicious for adenocarcinoma" (SEAC) is similar to EAC, but with scant cellularity and without necrosis. The sensitivity for the cytological diagnosis of HGD/EAC in esophageal brushing/ballooning in most studies ranges from $82 \%$ to $100 \% .^{31,32,40}$ In contrast, our observed sensitivity of $40 \%$ is much lower compared to most studies. The major problem is the lower cellularity in our study. As high as 37\% (18/49) of HGD and EAC cases showed only $0-3$ glandular groups in cell blocks, which presented difficulties in making definite cytological diagnosis. As we mentioned before, the improvement of sample collection is our major 
challenge for increasing the sensitivity of current tests. The cytological studies reporting greatest sensitivity uniformly used visually guided endoscopic brushings to collect the cytological samples. However, the need for endoscopy increases the cost and decreases the convenience of the test compared to the swallowable encapsulated sponge.

The patients in our study were from gastroenterological clinics, which is not representative of population scenario. The analysis of sensitivity and specificity also is limited since our patients are at high risk for BE or dysplasia. In future, we will screen the people in our population with several risk factors such as over 50-year-old, obese, GERD, smoking or alcoholic. Then, we can decide the sensitivity and specificity of our new method to screen the population.

\section{Conclusion}

Combining EsophaCap (TM) cytology with MUC2 immunohistochemistry has reasonable sensitivity and specificity for screening IM and beyond. However, the EsophaCap has low to moderate accuracy for detection of HGD and EAC, and would be unsuitable for use in a surveillance setting. In the future, combining cytology, MUC2 IHC and molecular (eg, genetic) tests may improve the accuracy for surveilling highrisk patients for HGD and EAC. In addition, improving EsophaCap sampling would also improve sensitivity and specificity.

\section{Abbreviation list}

AGC, atypical glandular cells; CCNGC, columnar cell with no goblet cell; CM, columnar metaplasia; EAC, esophageal adenocarcinoma; HGD, high-grade dysplasia; ID, indefinite dysplasia; IHC, immunohistochemistry; IM, intestinal metaplasia; IMNHGD, intestinal metaplasia with no high-grade dysplasia; LGD, lowgrade dysplasia; NCC, no or rare columnar cell; ND, non-diagnostic; SFEAC, suspicious for esophageal adenocarcinoma.

\section{Acknowledgments}

We want to thank all support from cytology technician, immunohistochemistry (Qi Yang and Loralee McMahon) and histology staffs at University of Rochester.

\section{Author contributions}

All authors contributed to data analysis, drafting and revising the article, gave final approval of the version to be published, and agree to be accountable for all aspects of the work.

\section{Disclosure}

The authors report no conflicts of interest in this work.

\section{References}

1. Pohl H, Sirovich B, Welch HG. Esophageal adenocarcinoma incidence: are we reaching the peak? Cancer Epidemiol Biomarkers Prev. 2010;19(6):1468-1470. doi:10.1158/1055-9965.EPI-10-0012

2. Njei B, McCarty TR, Birk JW. Trends in esophageal cancer survival in United States adults from 1973 to 2009: a SEER database analysis. J Gastroenterol Hepatol. 2016;31(6):1141-1146. doi:10.1111/ jgh.13289

3. Pohl H, Welch HG. The role of overdiagnosis and reclassification in the marked increase of esophageal adenocarcinoma incidence. $J$ Natl Cancer Inst. 2005;97(2):142-146. doi:10.1093/jnci/dji024

4. Reynolds JV, Donohoe CL, McGillycuddy E, et al. Evolving progress in oncologic and operative outcomes for esophageal and junctional cancer: lessons from the experience of a high-volume center. $J$ Thorac Cardiovasc Surg. 2012;143(5):1130-1137 e1131. doi:10.1016/j.jtcvs.2011.12.003

5. Modiano N, Gerson LB. Barrett's esophagus: incidence, etiology, pathophysiology, prevention and treatment. Ther Clin Risk Manag. 2007;3(6):1035-1145.

6. Rex DK, Cummings OW, Shaw M, et al. Screening for Barrett's esophagus in colonoscopy patients with and without heartburn. Gastroenterology. 2003;125(6):1670-1677.

7. Jankowski J, Bennett C, Jankowski JA. Management of Barrett esophagus: a practical guide for clinicians based on the BADCAT and BoB CAT recommendations. Pol Arch Med Wewn. 2015;125 (10):765-770

8. Hvid-Jensen F, Pedersen L, Drewes AM, Sorensen HT, FunchJensen P. Incidence of adenocarcinoma among patients with Barrett's esophagus. N Engl J Med. 2011;365(15):1375-1383. doi:10.1056/NEJMoa1103042

9. Bhat S, Coleman HG, Yousef F, et al. Risk of malignant progression in Barrett's esophagus patients: results from a large population-based study. J Natl Cancer Inst. 2011;103(13):1049-1057. doi:10.1093/ jnci/djr203

10. Pohl H, Pech O, Arash H, et al. Length of Barrett's oesophagus and cancer risk: implications from a large sample of patients with early oesophageal adenocarcinoma. Gut. 2016;65(2):196-201. doi:10.1136/ gutjnl-2015-309220

11. Shaheen NJ, Falk GW, Iyer PG, Gerson LB; American college of G. ACG clinical guideline: diagnosis and management of Barrett's Esophagus. Am J Gastroenterol. 2016;111(1):30-50;quiz 51. doi:10.1038/ajg.2015.322

12. Iwakiri K, Kinoshita Y, Habu Y, et al. Evidence-based clinical practice guidelines for gastroesophageal reflux disease 2015. J Gastroenterol. 2016;51(8):751-767. doi:10.1007/s00535-016-1227-8

13. Inadomi JM. Surveillance in Barrett's esophagus: a failed premise. Keio J Med. 2009;58(1):12-18.

14. Gerson LB. Cost-analyses studies in Barrett's Esophagus: what is their utility? Gastroenterol Clin North Am. 2015;44(2):425-438. doi:10.1016/j.gtc.2015.02.011 
15. Yu D, Hopman WM, Paterson WG. Wait time for endoscopic evaluation at a Canadian tertiary care centre: comparison with Canadian association of gastroenterology targets. Can J Gastroenterol. 2008;22 (7):621-626.

16. Sharma P, Katzka DA, Gupta N, et al. Quality indicators for the management of Barrett's esophagus, dysplasia, and esophageal adenocarcinoma: international consensus recommendations from the American gastroenterological association symposium. Gastroenterology. 2015;149 (6):1599-1606. doi:10.1053/j.gastro.2015.08.007

17. Spechler SJ, Sharma P, Souza RF, Inadomi JM, Shaheen NJ; American Gastroenterological A. American Gastroenterological association technical review on the management of Barrett's esophagus. Gastroenterology. 2011;140(3):e18-52;quiz e13. doi:10.1053/j. gastro.2011.01.031

18. Dulai GS, Guha S, Kahn KL, Gornbein J, Weinstein WM. Preoperative prevalence of Barrett's esophagus in esophageal adenocarcinoma: a systematic review. Gastroenterology. 2002;122(1):26-33.

19. Shen O, Liu SF, Dawsey SM, et al. Cytologic screening for esophageal cancer: results from 12,877 subjects from a high-risk population in China. Int J Cancer. 1993;54(2):185-188.

20. Liu SF, Shen Q, Dawsey SM, et al. Esophageal balloon cytology and subsequent risk of esophageal and gastric-cardia cancer in a high-risk Chinese population. Int J Cancer. 1994;57(6):775-780.

21. Adams L, Roth MJ, Abnet CC, et al. Promoter methylation in cytology specimens as an early detection marker for esophageal squamous dysplasia and early esophageal squamous cell carcinoma. Cancer Prev Res (Phila). 2008;1(5):357-361. doi:10.1158/19406207.CAPR-08-0061

22. Korsten MA, Worner TM, Feinman L, Shaw S, Federman Q. Balloon cytology in screening of asymptomatic alcoholics for esophageal cancer, Part I. Dig Dis Sci. 1985;30(9):845-851.

23. Tsang TK, Hidvegi D, Horth K, Ostrow JD. Reliability of balloon-mesh cytology in detecting esophageal carcinoma in a population of US veterans. Cancer. 1987;59(3):556-559.

24. Falk GW, Chittajallu R, Goldblum JR, et al. Surveillance of patients with Barrett's esophagus for dysplasia and cancer with balloon cytology. Gastroenterology. 1997;112(6):1787-1797.

25. Kadri SR, Lao-Sirieix P, O`Donovan M, et al. Acceptability and accuracy of a non-endoscopic screening test for Barrett's oesophagus in primary care: cohort study. BMJ. 2010;341:c4372. doi:10.1136/ bmj.c4372

26. Kadri S, Lao-Sirieix P, Fitzgerald RC. Developing a nonendoscopic screening test for Barrett's esophagus. Biomark Med. 2011;5 (3):397-404. doi:10.2217/bmm.11.40

27. Paterson AL, Lao-Sirieix P, O`Donovan M, et al. Range of pathologies diagnosed using a minimally invasive capsule sponge to evaluate patients with reflux symptoms. Histopathology. 2017;70(2):203-210. doi:10.1111/his.13039.
28. Leoni-Parvex S, Mihaescu A, Pellanda A, Monnier P, Bosman FT. Esophageal cytology in the follow-up of patients with treated upper aerodigestive tract malignancies. Cancer. 2000;90(1):10-16.

29. Katzka DA, Geno DM, Ravi A, et al. Accuracy, safety, and tolerability of tissue collection by Cytosponge vs endoscopy for evaluation of eosinophilic esophagitis. Clin Gastroenterol Hepatol. 2015;13 (1):77-83 e72. doi:10.1016/j.cgh.2014.06.026

30. Benaglia T, Sharples LD, Fitzgerald RC, Lyratzopoulos G. Health benefits and cost effectiveness of endoscopic and nonendoscopic cytosponge screening for Barrett's esophagus. Gastroenterology. 2013;144(1):62-73 e66. doi:10.1053/j.gastro.2012.09.060

31. Kumaravel A, Lopez R, Brainard J, Falk GW. Brush cytology vs. endoscopic biopsy for the surveillance of Barrett's esophagus. Endoscopy. 2010;42(10):800-805. doi:10.1055/s-0030-1255710

32. Geisinger KR, Teot LA, Richter JE. A comparative cytopathologic and histologic study of atypia, dysplasia, and adenocarcinoma in Barrett's esophagus. Cancer. 1992;69(1):8-16.

33. McIntire MG, Soucy G, Vaughan TL, Shahsafaei A, Odze RD. MUC2 is a highly specific marker of goblet cell metaplasia in the distal esophagus and gastroesophageal junction. Am J Surg Pathol. 2011;35(7):1007-1013. doi:10.1097/PAS.0b013e318218940d

34. Jaskiewicz K, Venter FS, Marasas WF. Cytopathology of the esophagus in Transkei. J Natl Cancer Inst. 1987;79(5):961-967.

35. Roshandel G, Merat S, Sotoudeh M, et al. Pilot study of cytological testing for oesophageal squamous cell dysplasia in a high-risk area in Northern Iran. Br J Cancer. 2014;111(12):2235-2241. doi:10.1038/ bjc. 2014.506

36. Wright TC Jr., Stoler MH, Behrens CM, Apple R, Derion T, Wright TL. The ATHENA human papillomavirus study: design, methods, and baseline results. Am J Obstet Gynecol. 2012;206 (1):46 e41-46 e11. doi:10.1016/j.ajog.2011.07.024

37. Mustafa RA, Santesso N, Khatib R, et al. Systematic reviews and meta-analyses of the accuracy of HPV tests, visual inspection with acetic acid, cytology, and colposcopy. Int $J$ Gynaecol Obstet. 2016;132(3):259-265. doi:10.1016/j.ijgo.2015.07.024

38. Montgomery E, Goldblum JR, Greenson JK, et al. Dysplasia as a predictive marker for invasive carcinoma in Barrett esophagus: a follow-up study based on 138 cases from a diagnostic variability study. Hum Pathol. 2001;32(4):379-388. doi:10.1053/ hupa.2001.23511

39. Kerkhof M, van Dekken H, Steyerberg EW, et al. Grading of dysplasia in Barrett's oesophagus: substantial interobserver variation between general and gastrointestinal pathologists. Histopathology. 2007;50(7):920-927. doi:10.1111/j.1365-2559.2007.02706.x

40. Saad RS, Mahood LK, Clary KM, Liu Y, Silverman JF, Raab SS. Role of cytology in the diagnosis of Barrett's esophagus and associated neoplasia. Diagn Cytopathol. 2003;29(3):130-135. doi:10.1002/ dc. 10334
Clinical and Experimental Gastroenterology

\section{Publish your work in this journal}

Clinical and Experimental Gastroenterology is an international, peerreviewed, open access, online journal publishing original research, reports, editorials, reviews and commentaries on all aspects of gastroenterology in the clinic and laboratory. This journal is indexed on American Chemical Society's Chemical Abstracts Service (CAS).
The manuscript management system is completely online and includes a very quick and fair peer-review system, which is all easy to use. Visit http://www.dovepress.com/testimonials.php to read real quotes from published authors. 